\title{
REFLEXIONES SOBRE LA EXPERIENCIA ESTÉTICA
}

Alejandro Tomasini Bassols

instituto de Investigaciones Filosóficas, unam

No hay investigación, filosófica o científica, que no tienda o aspire a dar cuenta, en un sentido o en otro, de algún aspecto de la realidad Independientemente de cómo se le interprete, hay indudablemente, por ejemplo, algo como experiencia mística y toda filosofía que se rehúse a dar cuenta de ella carece por completo de interés, por lo menos en el ámbito relevante, es decir (en este caso), la filosofía de la religión. Bien puede ser que no haya Dios alguno y que, por lo tanto, no haya, como quieren los místicos, ese especial contacto con el Ser Supremo del cual ellos hablan, pero esto no implica que la experiencia del religioso, que se manifiesta linguísticamente en un esfuerzo por expresar algo importante y profundo sobre el mundo considerado como un todo, sobre la experiencia del mundo, el sentido de la vida, la maravilla de la auto-conciencia, etcétera, sea un mero fraude, un simple "error", el resultado de alguna incomprensión. trivial de la "lógica" de nuestro lenguaje, etc. Cuando el místico toma la palabra lo que le sucede es que se da cuenta de que su especialísima experiencia se rehúsa a ser descrita en el mismo lenguaje en el que podría serlo cualquier experiencia común. Uno de sus recursos es entonces la palabra "Dios". Que dicha palabra denote o no una entidad y que se pueda o no tomar literaimente lo que el místico afirma son cuestiones que, independientemente de la actitud y posición que con respecto a ellas se adopte, no alteran en lo más mínimo el valor y la importancia de lo expresado por el religioso. La labor del filósofo en este caso es únicamente de elucidación. El filósofo no es ninguna autoridad para decidir si puede haber o no experiencia mística.

Ahora bien, lo mismo sucede con la experiencia estética. Podemos, pienso, afirmar que cualquier sisţema filosófico que niegue que hay lo que llamamos "experiencia estética" y que rehúse o no pueda dar cuenta de ella, es sencillamente falso y podemos desecharlo con toda tranquilidad. Así, pues, nuestra asunción aquí es la aceptación, dócil y total, de la experiencia estética. Partimos de la innegable solidez de su realidad. Nuestro problema, por lo tanto, será explicarla, describirla, no tratar de determinar si existe o no, si es o no posible.

Podemos, para empezar, caracterizar a la experiencia estética como la contemplación deleitosa de ciertos objetos (o de cierta clase de objetos) 
y/o del mundo, cuando éste es "visto" desde cierta "perspectiva" "Como es natural, para poder determinar qué tan acertada es dicha caracterización necesitamos tener bien claro qué es lo que se está afirmando y ello, a su vez, requiere que aclaremos lo que queremos decir por "contemplación", "deleitosa" y "perspectiva". Empecemos por "contemplación".

Lo primero que hay que decir es que "contemplación" no es nada más un mero sinónimo de "observación". El primero es un concepto mucho más amplio y tiene, por lo menos, dos sentidos. Cuando "contemplación" es usado con referencia a la experiencia sensible, entonces sí es un sinónimo de "observación". En este caso, ambos términos son empleados básicamente para hablar de experiencias visuales. Por ello, en general, no decimos que podemos contemplar auditiva o táctilmente el mundo. Pero también es cierto que no todo lo que observamos lo contemplamos. La razón es que contemplamos algo cuando lo "observamos" de cierta manera (con detenimiento, por ejemplo) y, más importante aún, con comprensión. En este segundo sentido de "contemplación" nos hemos elevado sobre o desligado del plano puramente sensorial. Pero si lo esencial de la contemplación en este segundo sentido es la comprensión, entonces ciertamente podemos "contemplar" procesos, fenómenos o cosas con las que entramos en contacto a través de los diversos sentidos. Aquí sí ya nos encontramos en el nivel o en el ámbito de la contemplación estética. Ahora bien, lo que hemos dicho tiene importantes consecuencias que es preciso extraer y examinar.

Se desprenden de lo que hemos dicho acerca de la contemplación estética por lo menos dos cosas:

a) que es activa

b) que es compleja

El primer punto es importante porque quien lo acepta se separa brusca, radical y definitivamente de una muy fuerte tradición de acuerdo con la cual el sujeto que mantiene una relación estética con algo recibe pasivamente una cierta dosis de estímulos, y sería en este recibir de data que consistiría la contemplación estética. De acuerdo con este enfoque, la diferencia entre contemplación no-estética u observación y contemplación estética procedería de o consistiría o radicaría en la organización objetiva de los datos sensoriales, es decir, en sus relaciones. Ciertas combinaciones de colores nos deleitan y otras no, ciertas sucesiones de notas nos placen y otras no, etc. La explicación derivada de dicho análisis formal es obviamente insatisfactoria y no sólo no sirve para distinguir la contemplación estética de la no-estética, como lo demuestra claramente la historia del 
tema, sino que además presupone que la percepción sensorial es de sensedata. Este último error inccrporado en la estética convencional no nos concierne aquí, pero es útil señalarlo para dirigirnos desde ahora en dirección contraria. En relación con nuestro problema, es claro que el enfoque formal es inoperante y carente de poder explicativo, entre otras razones porque deja fuera precisamente las condiciones sine qua non de eso que no es más que el estadio último de la contemplación estética y que es en lo que él (i.e. el análisis formal) se concentra. Es evidente que ni la más sublime sinfonía podría impresionar estéticamente a un hombre sin cultura musical, al igual que no podría impresionar a un caballo. Asumiendo sin discutir que en la observación el sujeto es pasivo, la difetencia entre observación y contemplación estética queda claramente marcada por el hecho de que esta última varía en función de los "conocimientos" relevantes de que se disponga. A diferencia de la observación "pura", la contemplación estética requiere o presupone una cierta educación, un cierto entrenamiento. E1 placer estético genuino es siempre justificable y, obviamente, no tiene sentido hablar de justificación en el caso de la mera observación, por placentera que ésta sea. No sólo hay una gran diferencia entre placer estético y placer sensorial, sino que, quizá, como ha sido mantenido por ejemplo por Schopenhauer y Freud, cuando se produce uno se extingue el otro. Cuando queremos expresar lingüisticamente nuestra satisfacción sensorial empleamos frases u oraciones como "me encanta", "qué bonito", y otras parecidas. Fórmulas como éstas nunca (o casi nunca) son usadas para expresar satisfacción estética y, en todo caso, son redundantes. El criterio para determinar si alguien ha gozado una experiencia estética es el hecho de que el sujeto ofrece razones que son, como veremos, descripciones, y estas descripciones son lo que nos explica su estado de éxtasis, hilatidad, emoción, placer, etc. Así, pues, la contemplación estética es activa en el sentido de que un sujeto pueda gozarla si y solamente si recurre a y hace uso de su bagaje de datos históricos, sicológicos y técnicos sobre el tema, los cuales le permitirán interpretar lo que ve, oye, explicar qué es lo que en el objeto le llama la atención, describir el objeto de muchas y variadas maneras, etc. Esto, curiosamente, es exactamente lo contrario de lo mantenido por ejemplo por los positivistas lógicos, lo cual explica por qué nunca pudieron ellos desarrollar una estética.

Hemos visto en qué sentido la contemplación estética es activa. Debemos ahora decir algunas palabras acerca de su complejidad.

La complejidad de la experiencia estética se revela en que ésta sólo surge con la capacidad discursiva de ofrecer razones, la cual a su vez presupone manejo de datos, "teorías", etc. La experiencia estética requiere 
conceptos estéticos. Estos constituyen la cultura estética del sujeto. No hay experiencia estética sin (potencial) emisión de juicios estéticos, es decir, descripción detallada, técnica, del objeto contemplado. La sensibilidad estética es la capacidad de apreciación de una obra de arte y nuestro criterio para decidir si alguien tiene o no dicha capacidad, o sea, si alguien es o no sensible, nos lo proporciona el sujeto a través de lo que él dice. No necesitamos apelar a refinadas facultades mentales, a intuiciones, a vibraciones de ninguna índole, para dar cuenta de la sensibilidad estética. Imaginemos, por ejemplo, a dos personas frente a "El conductor de Delfos". Uno de ellos ve la escultura, le da quizá la vuelta y culmina su inspección con "Qué hermoso" o alguna expresión equivalente. El otro no emplea lenguaje evaluativo, pero describe lo que contempla: lo que él imagina eran las intenciones del artista, las proporciones de la obra, los colores y las formas, lo que en su imaginación son las partes faltantes, etc. Claramente, el segundo y no el primero ha gozado una experiencia estética, a pesar de no haber emitido ningún "qué hermoso". Así, aunque la experiencia estética no es matematizable (es decir, no es automático que tiene una mejor experiencia alguien que habla más que otras gentes; también existe lo que llamamos "charlatanería"), dicha experiencia sí es, en algún sentido, medible. La cantidad de cosas que alguien puede decir sobre un cuadro es importante, pero también lo son la originalidad del comentario, el modo como éste es efectuado, los gestos que lo acompañan, etc. Lo que ha confundido (y sigue haciéndolo) a los filósofos es el hecho de que hay efectivamente una estrecha conexión entre sensibilidad y goce estético. Sobre esto regresaremos más adelante, pero, por el momento, podemos reafirmar que, como vimos, "me gusta" o "qué hermoso" no expresan goce estético, sino mero goce sensorial. Por ello, la implicación importante en estética es:

$$
\mathrm{D}_{1}, \mathrm{D}_{2}, \mathrm{D}_{3} \ldots \mathrm{D}_{\mathrm{n}} \longrightarrow \text { "Ya comprendo" }
$$

y no

$\mathrm{D}_{1}, \mathrm{D}_{2}, \mathrm{D}_{3} \ldots \ldots \mathrm{D}_{\mathrm{n}} \longrightarrow$ "Me gusta"

De "Ya comprendo" podemos pasar a discutir si algo es una gran obra o nada extraordinario, pero estas últimas expresiones están en otro nivel semántico que las mismas oraciones usadas en conexión con los objetos de la observación. Así, pues, tenemos:

$\left(D_{1}, D_{2}, D_{3} \ldots D_{n}\right) \longrightarrow$ "Ya comprendo") — Evaluación estética. 
pero $\left(\left(D_{1}, D_{2}, D_{3}, \ldots D_{n}-\right.\right.$ "Me gusta") - Evaluación (es un

Es muy importante y difícil distinguir entre placer estético y placer noestético. Es difícil porque el placer estético, aunque tendiente a independizarse de la sensación, sí requiere de los sentidos para poder tener lugar. Necesitamos ver un cuadro para poder admirarlo, escuchar un cuarteto para poder disfrutarlo. Esto es lo que ha llevado a las personas a creer que el placer estético consiste en el ver, en el escuchar, etc. Pero esto no pasa de ser un grotesco error. El placer estético es, básicamente, un placer de comprensión y de creación. Como el matemático, el artista crea algo y fija un estándar, en tanto que el observador, como el aprendiz en matemáticas, estudia la obra tratando de comprenderla. En ambos casos hay placer estético (i.e. los casos del observador y del creador), pero en ningún caso se trata de un mero placer sensorial. Hay, pues, dos clases de placeres estéticos, el del creador o educador (i.e. el artista) y el del educado. Los estetas se han contentado con hablarnos del placer estético en general, sin trazar la distinción recién hecha y que tiene, como veremos a continuación, no desdeñables consecuencias.

Se nos plantea, pues, el problema de la comunicación entre el artista y el espectador, la cuestión del acuerdo y el desacuerdo en arte y el de naturaleza misma de la obra de arte. Ello requiere que consideremos artes particulares y tal vez casos concretos de obras de arte.

Examinemos primero el caso de la música. Aquí un cierto (y claro) paralelismo interesante puede trazarse con relación a las matemáticas. Dada la institución de la música, lo que un artista hace es desarrollarla en una cierta dirección mediante la construcción de patrones, esquemas o estructuras musicales que, si pasan los tests de los especialistas, los metemos, como diría Wittgenstein, en el cajón. Hay un desarrollo inmanente de la música con fijos límites establecidos por la realidad material (e.g. no podía haber habido música electrónica en tiempos de Bach y, por lo tanto, un simúmero de combinaciones de sonidos eran inimaginables para todo mundo). Ahora bien, en cualquier etapa de su desarrollo son los técnicos o especialistas en la materia quienes deciden si algo nuevo es o no valioso (novedoso). En el reino de la matemática, por ejemplo, hay dos clases de matemáticos:

1) los grandes matemáticos

2) los continuadores de sus obras 
Un gran matemático es aquel que establece una nueva base, un nuevo punto de partida en algún área de la matemática. Un continuador es alguien que extrae conclusiones de los resultados del gran matemático (Gödel, por ejemplo, es un gran matemático). Ahora bien, deseo mantener que lo mismo sucede en música. Mozatt y Haydn son grandes músicos porque ellos "crearon" lo que se conoce como "música clásica". Los continuadores son quienes trabajaron dentro del marco creado por esos dos grandes artistas. En general, el músico crea algo que transmite a algunos iniciadores, quienes juzgan su obra y la difunden. Lo que esto quiere decir es que tratan de hacer ver a quienes no son músicos en qué consiste lo grande, lo importante de la obra, ubicándose desde el principio en el contexto mismo de la música, es decir, manejando un sinnúmero de criterios formales o internos a las composiciones musicales. Si alguien cuestionara o rechazara la institución de la música, como Platón lo hizo con la poesía, no habría manera alguna de demostrar nada. Pero éste nunca ha sido, hasta donde yo sé, el caso. Dada la institución de la música y metidos en ella, de lo que se trata es de desarrollarla y comprenderla o apreciarla y para ello las descripciones técnicas bastan. Dadas las innovaciones, las "sorpresas" musicales, etc. de una obra, se sigue o no se sigue que es grande, mediocre, etc. El practicante de la música, es decir, el intérprete, lleva al público, por así decirlo, de la mano, para que éste pueda apreciar lo pensado o concebido por el artista en un determinado "juego" o arte. En ambos casos, i.e. creación y apreciación, hay placer y ése es el placer estético. Podemos ahora preguntar: ¿qué es lo que el músico hace? Para responder a esta pregunta es conveniente concebir a la música y a las artes en general antropológicamente, es decir, como procesos humanos de educación. ¿Educación de qué? En el caso de la música, del sentido de oído.

Lo mismo sucede con la pintura. Lo que los pintores hacen es descubrir las potencialidades que se encuentran en la visión "en bruto". Cuando uno ve algo, uno puede querer fijarse en et objeto, en la luz, en la forma, en la impresión, en la idea de lo que se ve, en el trasfondo, en el espacio, etc. Todo eso está virualmente contenido en el acto de ver. Lo que el innovador en la pintura logra es plasmar en la tela uno o varios de los múltiples elementos del inmensamente rico fenómeno de ver. Así como el músico actualiza potencialidades auditivas, el pintor actualiza potencialidades visuales. La historia de la pintura muestra que el fenómeno "ver" abarca desde "ver bruto" hasta "ver conceptual". Los pin. tores nos enseñan, a través de sus obras, a ver el mundo enfatizando uno u otro de los factores involucrados en el proceso "ver". 
Más claro y general aún es el caso de la literatura. Los personajes literarios representan tipos humanos, posibilidades de acción y de pasión. Un ser humano puede ser tanto Don Quijote como James Bond. Lo que el literato hace es concebir las situaciones que permitan hacer explícitas las potencialidades del ser humano en general con respecto a la acción, decisión, pasión, etc. Al hacerlo, el literato educa al hombre porque amplía sus posibilidades, le enseña que también él podría ser esto o aquello, vivir de tal o cual manera, tener tal o cual experiencia.

Si 10 que he dicho es cietto, entonces se nos aclara un rasgo partict. larmente importante de la obra de arte: su a-temporalidad. Lo que sucede es que en el proceso de educación efectuado por el arte, los logros artís. ticos (como los obtenidos en otras áreas de la cultura) se van acumulando y se van incorporando a la vida social. Esta se va enriqueciendo precisamente porque no se pierden las contribuciones y las enseñanzas universales. El arte, definitivamente, revela verdades de manera no proposicional y las verdades son a-temporales. Esto aclara, pienso, un aspecto de la obra de arte que ha dado lugar a interminables especulaciones.

Quizá podamos ahora regresar a nuestra caracterización inicial y determinar si es adecuada o no. Por lo pronto, resulta claro que es incompleta, porque al hablar de contemplación hemos tenido en mente básicamente la satisfacción estética de quien disfruta una obra de arte, pero nos hemos olvidado del creador, es decir, del artista. Si hay placer estético intenso, es precisamente en él. Ahora bien, el arte consiste, grosso modo, en el desarrollo, en la dirección del refinamiento, de los diversos sentidos. Dicho desarrollo no puede efectuarse sin los utensilios necesarios, o sea, los conceptos correspondientes (asociados a técnicas, instrumentos, lenguaje, etc.). Un hombre sin educación estética, un hombre que no sabe lo que es el contrapunto o el claro-oscuro, que no ha vivido las experiencias de Alíosha Karamozow o de Eduardo y Charlotte, es como un hombre con manos desmesuradamente toscas, callosas y rudas: una infinidad de actividades y sensaciones le están vedadas. El artista es el creador de conceptos y quien, usándolos, amplía las posibilidades humanas de experiencia sensorial. El artista crea nueva sensibilidad o, mejor dicho, un mundo nuevo para el ejercicio de una nueva sensibilidad (la sensibilidad conceptualizada). El arte es combinación evolutiva de sentidos y conceptos, es la educación de los sentidos. Me parece que aquí sólo una metáfora puede expresar los efectos de una obra de arte y diferenciarlos de los placeres sensuales "brutos": la de los niveles de lenguaje. "Me gusta" expresa placer sensorial y no se deriva de nada si es sólo el reemplazante de un grito "Me gusta" expresa placer estético y es legítimo 
afirmarlo cuando se tienen a la mano las razones que justifican la emisión de la expresión.

Hay un último punto que me parece interesante, ya que a través de él conectamos a la estética con la ética. En general, hemos hablado de contemplación de objetos de arte, i.e. de objetos creados por el hombre para su consumo y deleite, pero también incluimos, en nuestra definición original, al mundo. Hablamos, en efecto, de contemplación estética con respecto al mundo como un todo. La idea que quiero presentar aquí es que descubrimos realmente la belleza en los objetos del mundo (y no sólo en crepúsculos o albas), sino en toda clase de paisajes, animales, tipos humanos, en los verdes de los bosques y en los azules de mares y cielos, cuando aceptamos al mundo tal cual es, cuando éste nos parece "perfecto". Esta contemplación estética (difícil sería hablar en este caso de creación), es superior al deleite producido por las obras de arte, por maravillosas que éstas sean. A final de cuentas, si bien son de grado distinto y son impuros, en el sentido de que mezclan sensaciones y pensamiento, los placeres estéticos generados por las obras de arte están irremisiblemente ligados a y al servicio de los sentidos y la sensualidad. El placer estético supremo, en cambio, o sea aquel tendiente a la supresión y no a la exaltación del yo y que consiste en la admiración gozosa del mundo que nos rodea, del mundo qua mundo, nos desliga de los placeres sensuales y tiende a confundirse, allá en el horizonte, con el éxtasis religioso. Es quizá porque valoro más a la literatura que a cualquier otro arte (música inclusive) que hombres como Tolstoy y Goethe me parecen los artistas divincs par excellence, los verdaderos hijos de Dios. Porque ellos pusieron su arte al servicio no de los sentidos sino de la ética y la religión, para poder disfrutar de manera más indiscriminada y general al mundo en su totalidad y a la vida, y eso parece ser algo que en principio ningún otro arte está capacitado para lograr. 